\title{
EFFECTS OF ISCHEMIA-REPERFUSION ON RAT RENAL TISSUE ANTIOXIDANT SYSTEMS AND LIPID PEROXIDATION
}

\author{
B. Rasoulian $^{* 1,2}$, M. Jafari ${ }^{3,4}$, A. Noroozzadeh ${ }^{5}$, H. Mehrani ${ }^{4}$, H. Wahhab-Aghai ${ }^{3,5}$, S. M. H. Hashemi-Madani ${ }^{6}$, \\ E. Ghani ${ }^{5}$, M. Esmaili ${ }^{7}$, A. Asgari ${ }^{5}$ and A. Khoshbaten $^{5,8}$
}

1) Razi Herbal Medicines Research Center and Department of Physiology, Lorestan University (Medical sciences), Khorramabad, Iran

2) Department of Physiology, School of Medicine, Lorestan University (Medical Sciences), Khorramabad, Iran

3) Trauma Research Center, Baqiyatallah University of Medical Sciences, Tehran, Iran

4) Department of Biochemistry, School of Medicine, Baqiyatallah University of Medical Sciences, Tehran, Iran

5) Department of Physiology and Biophysics, School of Medicine, Baqiyatallah University of Medical Sciences, Tehran, Iran

6) Research Center for Molecular Biology, School of Medicine, Baqiyatallah University of Medical Sciences, Tehran, Iran

7) Department of Physiology, School of Medicine, Yazd University of Medical Sciences, Yazd, Iran

8) Research Center for Chemical Injuries, School of Medicine, Baqiyatallah University Medical Sciences, Tehran, Iran

\begin{abstract}
Renal ischemia-reperfusion (IR) injury is a common problem in kidney transplantation. There is increasing evidence about the role of the reactive oxygen species (ROS) in these injuries and endogenous antioxidants seem to have an important role in decreasing the renal tissue injury. The aim of this study was to investigate the effects of kidney IR on renal antioxidant enzymes activity such as catalase and superoxide dismutase (SOD) and renal glutathione (GSH) levels. The level of malondialdehyde (MDA), an end product of lipid peroxidation, also was quantified. Male Wister rats (200-280 g) were anesthetized and after right nephrectomy, the left renal artery was clamped for 40 min. After $24 \mathrm{~h}$ reperfusion, serum and kidney tissue samples were obtained for metabolites assay. Results showed that renal IR increased serum creatinine and urea level [90.59 \pm 12.93 vs. $44.06 \pm 4.07$ $\mu \mathrm{mol} / \mathrm{L}(P<0.01)$, and $40.22 \pm 10.27$ vs. $20.8 \pm 1.8 \mathrm{mmol} / \mathrm{L},(P<0.05)$, respectively]. The renal catalase activity was decreased (33.13 \pm 2.02 vs. $43.78 \pm 2.38$ units/mg protein, $P<0.01$ ) but SOD activity was increased (57.59 \pm 4.64 vs. $42.84 \pm 1.85$ units/mg protein, $P<0.05$ ). The GSH level also was decreased ( $24.67 \pm 2.31$ vs. $37.44 \pm 3.09 \mathrm{nmol} / \mathrm{mg}$ protein $P<0.01)$. MDA level after IR was not significantly different from control group ( $2.05 \pm 0.27$ vs. $1.84 \pm 0.2 \mathrm{nmol} / \mathrm{mg}$ protein, $P=0.55)$. Our data indicated that despite decrease in renal GSH level and catalase activity following IR, SOD activity was increased.

(C) 2008 Tehran University of Medical Sciences. All rights reserved.

Acta Medica Iranica 2008; 46(5): 353-360.
\end{abstract}

Key words: Kidney, ischemia, reperfusion, antioxidant, malondialdehyde

Received: 4 Sep. 2006, Revised: 27 Feb. 2007, Accepted: 3 Mar. 2007

* Corresponding Author:

Bahram Rasoulian, Razi Herbal Medicines Research Center,

Khorramabad, Iran

Tel: +98 6613204005

Fax: +98 6613204005

E-mail: bahramrasoulian@gmail.com

\section{INTRODUCTION}

Cellular hypoxia due to tissue ischemia is a hazardous event which if extended, could inevitably lead to cellular damage and necrosis. Paradoxically, re-oxygenation due to reperfusion causes tissue 
injury (1-2). Renal tissue ischemia-reperfusion (IR) injury would occurs in some important clinical circumstances such as "severe hypotension and subsequent resuscitation", "kidney transplantation" and "aortovascular surgeries", that all could lead to acute renal failure (ARF) (1). ARF has relatively high incidence rate in hospitalized patients (3) and the most prevalent causes are ischemic events (4). For example, ARF rate following aortovascular surgeries is reported to be as high as $50 \%$ (5) and $4-15 \%$ after coronary bypass (3).

The numbers of kidney transplantation surgeries are increasing in Iran and only in year 2000 over 1400 kidney transplantations have been performed (6). In two recent studies in Iran, ARF rates in surgical emergency room and ICU section were $5.66 \%$ and 21\%, respectively (7). Despite high incidence of ARF, there has not been any remarkable improvement so far in reducing its mortality rate from the time of Korean war since about half a century ago (8). The inevitable IR event in kidney transplantation also may lead to acute tubular necrosis which is responsible for $90 \%$ of ARF cases in first week of transplantation (9). ARF rate after kidney transplantation has been reported to be $5 \%$ to $50 \%$ (10) and IR-induced ARF has been associated with delayed graft function and decrease in allograft survival (3-4).

One of the most important factors in pathophysiology of renal IR injury is reactive oxygen species (ROS), which especially increases in reperfusion phase $(4,11)$. The endogenous antioxidants which are responsible for defense against ROS during reperfusion have an important role in decreasing IR injury (2). Superoxide dismutase (SOD) and catalase (CAT) are the most important antioxidant enzymes of tissues (12). Glutathione (GSH), a free radical scavenger (13), plays a key role in maintenance of the cellular redox environment (14). Taking into account the importance of ARF in clinical situation, recognizing IR effects on antioxidant enzymes activities and GSH level may help to find a better strategy for prevention and/or therapy of ischemic ARF.
Previous studies mostly emphasize on suppression of nearly all antioxidant defense mechanisms including lower activities of SOD and catalase and lower GSH level after IR (2). However, there is controversy especially in the case of SOD (5, 15-18). On the other hand, one of the mechanisms of ROS induced IR injury is lipid peroxidation and malondialdehyde (MDA) level is a good indicator of this process $(2,19)$.

The purpose of this study was to investigate the effects of ischemia and reperfusion on SOD and catalase activities and GSH and MDA levels in rat renal tissue.

\section{MATERIALS AND METHODS}

All chemicals were purchased from Sigma and Merck Chemical companies. Adult male Wister rats (200-280 g) were obtained from Baqiyatallah University animal house and were maintained at $25^{\circ} \mathrm{C}$ and had free access to rodent food and water. All interventions in animals were provided in accordance with the protocol approved by Baqiyatallah University of Medical Sciences Animal Care and by National Iranian Ministry of Health.

Animals were divided into two groups: control (n $=11)$ and IR $(\mathrm{n}=10)$. They were anesthetized using intraperitoneal (ip) injection of sodium pentobarbital (50 mg/kg body weight). Then $300 \mathrm{U}$ of heparin and $0.5 \mathrm{ml}$ normal saline were delivered through ip injection. Anesthetized rats were placed on a surgical table. Using an electrical heater and a warming light the temperature was adjusted to near $37^{\circ} \mathrm{C}$. Animals were allowed to spontaneously breathe room air. Midline laparotomy and right nephrectomy (after ligating the vascular pedicle with two pieces of a 2-0 silk) were performed. Then, left renal artery and vein were gently separated and after a 30-min of stabilization period, renal artery was clamped in IR group using a spring microvascular clamp, in order to induce ischemia. The clamp was removed after 40 min and abdominal wall was then closed with a 2-0 prolene 20 min later. In the control group, all steps were similar to IR group except for the use of clamp to induce ischemia. 
The animals were anesthetized again 24 hours postoperatively and after clamping the pedicle, the left kidney was removed. Blood samples were obtained from aorta and then serum was separated for urea and creatinine assay. Inferior one third of the kidney was immediately washed with normal saline and frozen in liquid nitrogen for GSH, MDA, SOD and catalase assays. Serum and tissue samples were kept in $-18^{\circ} \mathrm{C}$ and $-70^{\circ} \mathrm{C}$, respectively, until the assays. IR was confirmed by observing kidney color changes, and in majority of rats (70\%) microcirculatory blood flow in the renal cortex was measured by a laser Doppler flowmeter (Moore Instruments, MBF3) in three distinct defined locations (two points in upper and lower halves of anterior surface and one point in posterior surface of the kidney). Care was taken for the points to have almost the same positions in all measurements.

The mean value of flow in these 3 points was considered as "mean microcirculatory blood flow". Mean microcirculatory blood flow in IR group was measured in six different conditions: 1) premanipulation (before isolating left renal artery and vein), 2) pre-ischemia, 3) three minutes after ischemia, 4) 37 minutes after ischemia, 5) $20 \mathrm{~min}$ after reperfusion, and 6) 24 hours after reperfusion. In control group, mean microcirculatory blood flow was measured at the same times as in IR group and named flow in conditions 1-6 respectively. These flows, being meașured by a laser Doppler flow meter, did not have any specific unit.

\section{Urea and creatinine measurement}

Serum urea was measured manually with urease using Berthelot procedure (ZistChem kit, Iran). Serum creatinine was measured by Jaffe reaction using autoanalyzer (Parsazmon kit, Iran).

\section{Tissue preparation}

Frozen tissue samples were quickly weighed and homogenized 1:10 in ice-cold $50 \mathrm{mM}$ potassium phosphate buffer ( $\mathrm{pH}$ 7.4) containing 1 mM EDTA and proteases inhibitors. The homogenates were then centrifuged at $12000 \mathrm{~g}$ for $15 \mathrm{~min}$ at $4^{\circ} \mathrm{C}$. The supernatants were taken and used for enzyme, MDA, GSH and protein assay.

\section{GSH and MDA determination}

MDA production was quantified according to Ohkawa procedure (19). GSH level was determined by the method of Tietze (20).

\section{Catalase and SOD activity assay}

Catalase activity in kidney tissue homogenates was measured by a colorimetric method as described previously by Cohen (21). The SOD activity was determined according to Paoletti method (22).

\section{Protein assay}

Total protein concentration was measured by Bradford's method (23) using bovine serum albumin as standard.

\section{Statistical analysis}

Data are shown as mean \pm SEM. To compare SOD, catalase, GSH and MDA values, the independent variable t-test was used. General comparisons of flow data in IR or control groups were done with repeated measure ANOVA and paired- $t$ test was performed for comparison among different conditions in IR group. $P<0.05$ was considered as significant.

\section{RESULTS}

\section{Microcirculatory blood flow}

Mean values for flow in IR group are shown in Fig. $1 \mathrm{~A}$. In general, flow differences in IR group were significant $(P<0.001)$. Flows during ischemia were only $5-6 \%$ of pre-ischemia level and both were significantly different from pre-ischemia and $20 \mathrm{~min}$ after reperfusion $(P<0.001)$. Flow rates in $20 \mathrm{~min}$ after reperfusion and 24 hours after reperfusion were not significantly different from pre-ischemia and pre-manipulation flows respectively; although the '20 min after reperfusion/pre-ischemia' and '24 hours after reperfusion/pre-manipulation' flow ratios were 0.918 and 0.920 , respectively. Mean values for flow in control group are shown in Fig. 1B. Flow differences in control group were not significant. Pre-manipulation and pre-ischemia flow rates had not any significant difference in IR group as well as control group. 

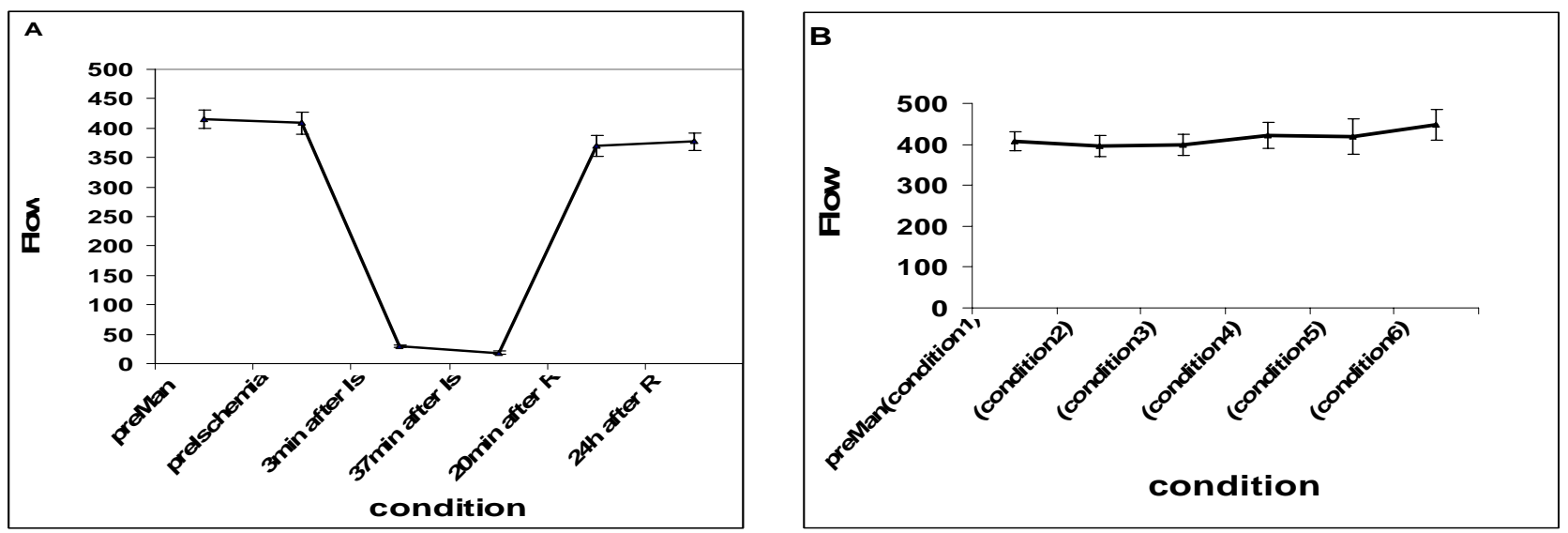

Fig. 1. Mean microcirculatory blood flow of renal cortex in IR group in 6 defined times (A) and in control group in the same times (conditions 1-6 respectively without any ischemia) (B). Blood flow was measured by a laser Doppler flowmeter. PreMan, premanipulation; Is, ischemia; R, reperfusion.

\section{Kidney function tests}

Serum creatinine level in IR group was higher than that of control group (Fig. 2A) $[90.59 \pm 12.93(\mathrm{n}=$ 8) vs. $44.06 \pm 4.07(\mathrm{n}=9) \mu \mathrm{mol} / \mathrm{L}, P=0.003]$. Serum urea also was significantly increased in IR group (Fig. 2B) $[40.22 \pm 10.27(\mathrm{n}=10)$ vs. $20.8 \pm$ $1.8(\mathrm{n}=11) \mathrm{mmol} / \mathrm{L}, P=0.013]$.

\section{Antioxidant enzymes activities}

Mean kidney tissue SOD activity in IR group was significantly higher than that of control group (Fig. 3A) $[57.59 \pm 4.64(n=7)$ vs. $42.84 \pm 1.85(n=7)$ units/mg protein, $P=0.012$ ]. But kidney tissue catalase activity in IR group was significantly lower than those of control group (Fig. 3B) $[33.13 \pm 2.02(\mathrm{n}=9)$ vs. $43.78 \pm 2.38(\mathrm{n}=8)$ units $/ \mathrm{mg}$ protein, $P=$ $0.004]$.

\section{GSH and MDA levels}

IR caused significant decrease in kidney tissue GSH level (Fig. 3C) $[24.67 \pm 2.31(\mathrm{n}=8)$ vs. 37.44 $\pm 3.09(\mathrm{n}=8) \mathrm{nmol} / \mathrm{mg}$ protein, $P=0.006$ ] but MDA levels in IR and control groups were not significantly different (Fig. 3D) $[2.05 \pm 0.27(\mathrm{n}=$ 7) vs. $1.84 \pm 0.2(\mathrm{n}=7) \mathrm{nmol} / \mathrm{mg}$ protein, $P=$ $0.55]$.
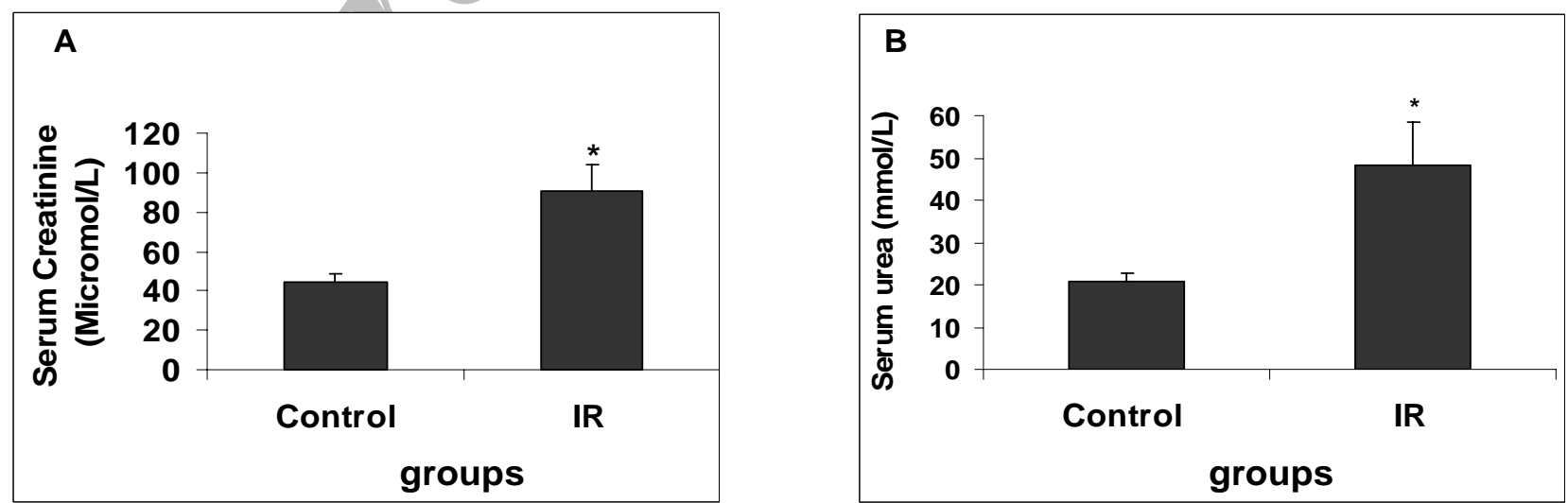

Fig. 2. Serum creatinine level in control and IR groups (A). Serum urea level in control and IR groups (B). *, $P<0.05$ compared to control group. 

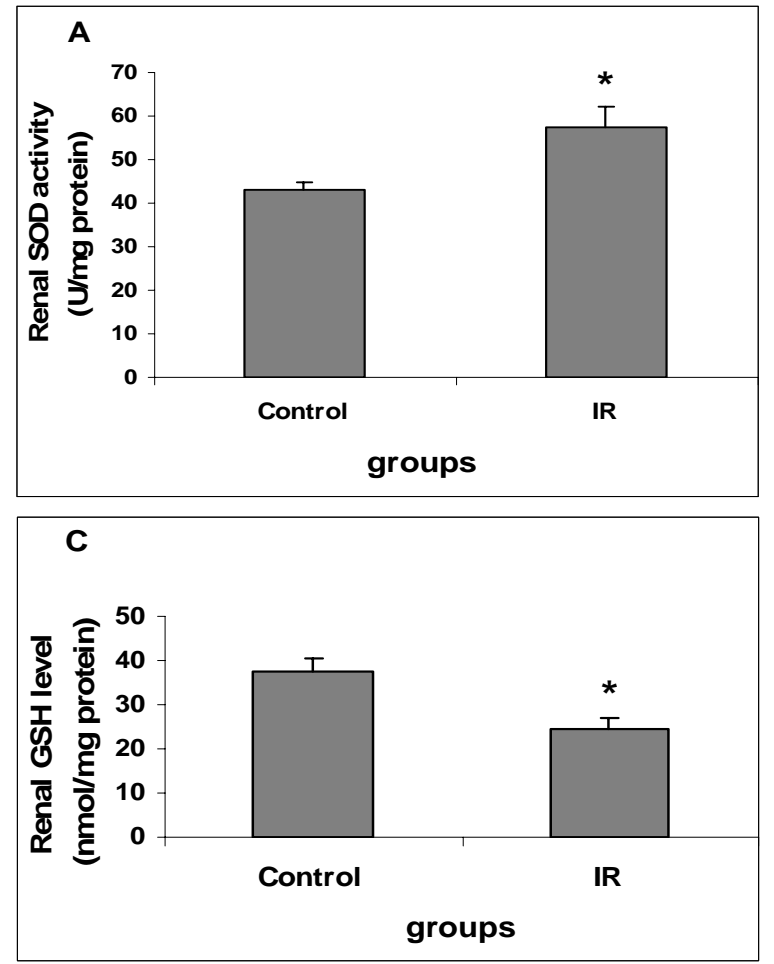
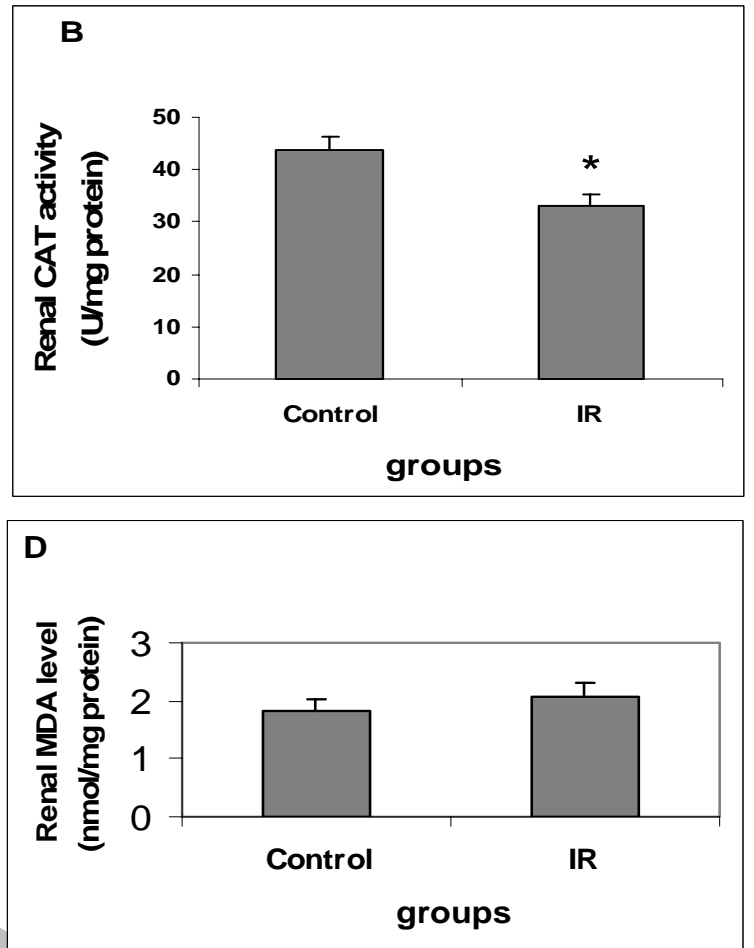

Fig. 3. Renal superoxide dismutase (SOD) activity (A) and catalase (CAT) activity (B); renal glutathione (GSH) (C) and malondialdehyde (MDA) (D) levels after 40 min of ischemia and 24 h reperfusion. *, $P<0.05$ compared to control group.

\section{DISCUSSION}

We examined the effects of ischemia and reperfusion on renal catalase and SOD activities as well as renal GSH and MDA levels. Data showed that in spite of a decrease in renal GSH level and catalase activity following IR, SOD activity was increased after IR. MDA level in IR group was not significantly different from that of control.

Pre-manipulation and pre-ischemia flows were nearly equal, showing that after nephrectomy and 30 min stabilization period, the condition seems appropriate for interventions such as ischemia. Decrease in blood flow during ischemia and increase after 20 min of reperfusion means that ischemia and reperfusion were established well. The insignificant difference between "pre-manipulation and 24 hours of reperfusion" and "pre-ischemia and 20 min of reperfusion” flow rates also indicates non-traumatic clamping of renal artery in this animal model. We also concluded that kidney color change during ischemia or reperfusion could be a very good indicator for confirmation of IR in our experiments.
Significant increase in both BUN and creatinine shows that 40 min ischemia and $24 \mathrm{~h}$ reperfusion resulted in serious renal injury. Similar results were obtained in previous studies $(24,25)$.

In present study, there was a decrease in renal GSH following kidney IR, as have been shown in other studies $(5,13,15,26)$. This decrease in GSH level could be explained by its consumption in scavenging free radicals and maintaining the redox state of the cell during IR injury (13-14). There are many evidences of ROS involvement in renal IR injury $(2,27,28)$ and both tubular and vascular endothelial cells are involved in ROS production (2). For example, renal proximal tubule cells show a 7fold increase in ROS production after hypoxiareoxygenation (29). Superoxide $\left(\mathrm{O}_{2}{ }^{-}\right)$radicals are among the most important free radicals responsible for IR injury. $\mathrm{O}_{2}{ }^{-}$is converted to hydrogen peroxide $\left(\mathrm{H}_{2} \mathrm{O}_{2}\right)$ by SOD and resulted $\mathrm{H}_{2} \mathrm{O}_{2}$ is inactivated by glutathione peroxidase (GPX) and catalase (4).

Decrease in renal catalase activity following IR in present study is similar to other published data, which remarked decrease in catalase activity as well 
as a reduction of its gene expression after IR $(15,20$, 17, 30). However, the mechanism for reduced catalase activity does not seem to be simply depletion of antioxidant pool as mentioned in one article (15). ROS produced during IR are considered as molecules interacting with physiological signal transductions, not simply reactants that peroxidize membrane lipids, or denature enzyme proteins. The general response to hypoxia is usually less gene expression and lower activity of antioxidant enzymes such as catalase, a predisposing factor for reoxygenation injury, although the mechanism by which hypoxia regulates expression of antioxidant enzymes is not well understood (2).

The increase in renal SOD activity in this study is surprising; because in studies reported by Chander (5), and Singh and Chander (15) renal SOD activity decreased following $45 \mathrm{~min}$ ischemia and $24 \mathrm{~h}$ reperfusion. However, a careful literature review clears interesting points in this regard. There was increased renal SOD activity after 30 min ischemia and 120 min reperfusion in Erdogan's study; although this increase was not significant (16). In Tenorio-Velazquez study, SOD activity was elevated in renal cortex (although insignificant) and diminished in outer medulla following $60 \mathrm{~min}$ ischemia and $24 \mathrm{~h}$ reperfusion (18). Since most of kidney SOD activity is related to renal cortex (31) and kidney samples in this study (inferior one third of kidney) was mostly from cortex, SOD activity in this model is mostly representative of the activity of this enzyme in renal cortex. It is more interesting that, in Singh et al. study, although total SOD activity was decreased after IR, manganese SOD (MnSOD) activity and its protein level were increased following IR. On the other hand, ischemia itself increased mRNA level of catalase, GPX and SOD; however after reperfusion, mRNA level of catalase and GPX decreased and at the same time SOD mRNA level remained high (17). It can be concluded that increased SOD activity in this study is most probably due to cortical MnSOD. As ischemia can increase SOD mRNA and SOD activity level may remain high during reperfusion (17), the severity of ischemia in our study (near complete loss of flow, Fig 1A) might be responsible for prominence of this process and significant increase in SOD activity after IR. Nevertheless, the end product of SOD is $\mathrm{H}_{2} \mathrm{O}_{2}$ which itself can lead to tissue injury either directly or via hydroxyl radical (OH-) formation by Fenton reaction (32).

Increased MDA level following IR was seen in some other studies in various models of kidney IR injury $(15,22)$. However, this increase in MDA level after IR was not seen in present study. Indeed, in the present study, ROS production and decreased catalase activity, and therefore pronounced formation of $\mathrm{H}_{2} \mathrm{O}_{2}$ during IR, could lead to increased lipid peroxidation, while increased SOD activity resulting in a decrease in $\mathrm{O}_{2}^{-}$could reduce lipid peroxidation. This might explain the insignificant changes in MDA level. Although the increased SOD activity also leads to increased $\mathrm{H}_{2} \mathrm{O}_{2}$ production, it should be taken into consideration that many $\mathrm{H}_{2} \mathrm{O}_{2}$ molecules diffuse rapidly from lipid membranes and cause oxidative stress in distant organs not in the kidney itself (33).

The important point of Erdogan (16), TenorioVelazquez (18) and especially Singh and Gulati (17) and our study is that in kidney IR, there is a potential of increased SOD activity. Understanding mechanisms responsible for this process and their potentiation may lead to better prevention or therapy of IR injury.

In summery, despite a decreased renal GSH level and catalase activity following kidney IR, consistent with nearly all similar experiments, renal SOD activity was increased after IR in this experiment. There were no significant changes in MDA level fallowing IR.

\section{Acknowledgments}

Authors would like to thank Mr. Asghar Ghasemi, Mrs. Bahareh Soleimani, Mr. Hasan Ghoshooni, Mrs Safie Otadi and Mr. Gholamreza Baqeri for their kind comments and helps. Financial support by Trauma Research Center of Baqiyatallah University of Medical Sciences and Lorestan University (Medical sciences) is gratefully acknowledged.

\section{Conflict of interests}

The authors declare that they have no competing interests. 


\section{REFERENCES}

1. Bouchier-Hayes DM, Fitzpatrick JM. In: Grace PA, Mathie RT. Ischemia-reperfusion injury. London: Black Well Science; 1999. P. 71-81.

2. Li C, Jackson RM. Reactive species mechanisms of cellular hypoxia-reoxygenation injury. Am J Physiol Cell Physiol. 2002 Feb;282(2):C227-241.

3. Thadhani R, Pascual M, Bonventre JV. Acute renal failure. N Engl J Med. 1996 May 30;334(22):14481460.

4. Paller MS, Hoidal JR, Ferris TF. Oxygen free radicals in ischemic acute renal failure in the rat. J Clin Invest. 1984 Oct; 74(4):1156-1164.

5. Chander V, Chopra K. Protective effect of nitric oxide pathway in resveratrol renal ischemiareperfusion injury in rats. Arch Med Res. 2006 Jan; 37(1):19-26.

6. Ghods AJ. Renal transplantation in Iran. Nephrol Dial Transplant. 2002 Feb; 17(2):222-228.

7. Fani A, Fani I, Jahani F, Amini M, Baghinia M, Rafiea M, Fahimi T. [The study of acute renal failure incidence in patients admitted to emergency surgical ward of Valie-Asr Hospital, Arak]. Journal of Arak University of Medical Sciences. 2005; 29: 27-32. [Farsi].

8. Schrier RW, Wang W, Poole B, Mitra A. Acute renal failure: definitions, diagnosis, pathogenesis, and therapy. J Clin Invest. 2004 Jul; 114(1):5-14.

9. Rao KV, Kjellstrand CM. Post transplant acute renal failure: a review. Clin Exp Dial Apheresis. 1983;7(12):127-143.

10. Tayho EA, McAninch JW. Smith's general urolagy. New York: McGraw-Hill; 2000. P. 617.

11. Weight SC, Bell PR, Nicholson ML. Renal ischaemia--reperfusion injury. Br J Surg. 1996 Feb; 83(2):162-170.

12. Berg JM, Tymoczko JL, Stryer L. Biochemistry. New York: W.H. Freeman and Company; 2002. P. 506-507.

13. Pincemail J, Defraigne JO, Detry O, Franssen C, Meurisse M, Limet R. Ischemia-reperfusion injury of rabbit kidney: comparative effects of desferrioxamine and N-acetylcysteine as antioxidants. Transplant Proc. 2000 Mar; 32(2):475-476.

14. Schafer FQ, Buettner GR. Redox environment of the cell as viewed through the redox state of the glutathione disulfide/glutathione couple. Free Radic Biol Med. 2001 Jun 1;30(11):1191-1212.
15. Singh D, Chander V, Chopra K. Protective effect of catechin on ischemia-reperfusion-induced renal injury in rats. Pharmacol Rep. 2005 Jan-Feb; 57(1):7076.

16. Erdogan H, Fadillioglu E, Yagmurca M, Uçar M, Irmak MK. Protein oxidation and lipid peroxidation after renal ischemia-reperfusion injury: protective effects of erdosteine and $\mathrm{N}$-acetylcysteine. Urol Res. 2006 Feb; 34(1):41-46.

17. Singh I, Gulati S, Orak JK, Singh AK. Expression of antioxidant enzymes in rat kidney during ischemiareperfusion injury. Mol Cell Biochem. 1993 Aug 25;125(2):97-104.

18. Tenorio-Velázquez VM, Barrera D, Franco M, Tapia E, Hernández-Pando R, Medina-Campos ON, PedrazaChaverri J. Hypothyroidism attenuates protein tyrosine nitration, oxidative stress and renal damage induced by ischemia and reperfusion: effect unrelated to antioxidant enzymes activities. BMC Nephrol. 2005 Nov 7;6: 12.

19. Ohkawa H, Ohishi N, Yagi K. Assay for lipid peroxides in animal tissues by thiobarbituric acid reaction. Anal Biochem. 1979 Jun; 95(2):351358.

20. Tietze F. Enzymic method for quantitative determination of nanogram amounts of total and oxidized glutathione: applications to mammalian blood and other tissues. Anal Biochem. 1969 Mar; 27(3):502522

20. Cohen G, Dembiec D, Marcus J. Measurement of catalase activity in tissue extracts. Anal Biochem. 1970 Mar; 34:30-38.

22. Paoletti F, Mocali A. Determination of superoxide dismutase activity by purely chemical system based on NAD(P)H oxidation. Methods Enzymol. 1990; 186:209-220.

23. Bradford MM. A rapid and sensitive method for the quantitation of microgram quantities of protein utilizing the principle of protein-dye binding. Anal Biochem. 1976 May 7;72:248-254.

24. Mohammadhosseniakbari H , Rasoulian B, Mofid M, Noroozzadeh A, Noroozi M, Behrahi F, Jabari M, Moradi Rad N, Jafari M, Shirkhani Y, Khoshbaten A. [The effect of short ischemic periods in reducing subsequent rat renal ischemic injury]. Physiology and Pharmacology. 2008 Summer; 12 (2): 149-157. [Farsi]. 
25. Rasoulian B, Mohammadhosseniakbari H, Kadkhodaee M, Mofid M, Baqeri G, Bigdeli MR, Ghasemi A, Mohebbi HA, Asgari A, Khoshbaten A. Preconditioning with oxygen attenuates rat renal ischemia-reperfusion injury. J Surg Res. 2008 May 15;146(2):282-288.

26. Rodríguez-Reynoso S, Leal C, Portilla-de Buen E, Castillo JC, Ramos-Solano F. Melatonin ameliorates renal ischemia/reperfusion injury. J Surg Res. 2004 Feb; 116(2):242-247.

27. Hirayama A, Nagase S, Ueda A, Oteki T, Takada K, Obara M, Inoue M, Yoh K, Hirayama K, Koyama A. In vivo imaging of oxidative stress in ischemia-reperfusion renal injury using electron paramagnetic resonance. Am J Physiol Renal Physiol. 2005 Mar; 288(3):F597603.

28. Kadkhodaee M, Hanson GR, Towner RA, Endre ZH. Detection of hydroxyl and carbon-centred radicals by EPR spectroscopy after ischaemia and reperfusion of the rat kidney. Free Radic Res. 1996 Jul; 25(1):31-42.
29. Paller MS, Neumann TV. Reactive oxygen species and rat renal epithelial cells during hypoxia and reoxygenation. Kidney Int. 1991 Dec; 40(6):10411049.

30. Sela S, Shasha SM, Mashiach E, Haj M, Kristal B, Shkolnik T. Effect of oxygen tension on activity of antioxidant enzymes and on renal function of the postischemic reperfused rat kidney. Nephron. 1993;63(2):199-206.

31. Gonzalez-Flecha B, Evelson P, Sterin-Speziale N, Boveris A. Hydrogen peroxide metabolism and oxidative stress in cortical, medullary and papillary zones of rat kidney. Biochim Biophys Acta. 1993 Jun 11;1157(2):155-161.

32. Grace PA. Ischaemia-reperfusion injury. $\mathrm{Br} \mathrm{J}$ Surg. 1994 May; 81(5):637-647.

33. Nath KA, Norby SM. Reactive oxygen species and acute renal failure. Am J Med. 2000 Dec 1;109(8):665678. 